\title{
In vitro evaluation of double carbapenem and colistin combinations against OXA-48, NDM carbapenemase-producing colistin- resistant Klebsiella pneumoniae strains
}

\author{
Fatma Erdem ${ }^{1 *}$, Ayham Abulaila², Zerrin Aktas $^{2}$ and Oral Oncul ${ }^{3}$
}

\begin{abstract}
Background: Treatment of pandrug-resistant isolates often necessitates combination therapy. Checkerboard synergy and time-killing assay tests were performed to evaluate the benefits of a triple combination with meropenem, ertapenem, and colistin against 10 colistin-resistant $K$. pneumoniae clinical isolates harboring different $\beta$-lactamases. (bla $\mathrm{OXA}-48$, blanDM).

Materials and methods: In this study, ertapenem and meropenem (ERT/MEM), meropenem and colistin (MEM/ $\mathrm{COL}$ ), ertapenem, meropenem and colistin (ERT/MEM/COL) combinations were tested using checkerboard techniques and time-kill assays of each antibiotic alone and in combination against 10 colistin-resistant clinical $K$. pneumoniae isolates. An analysis of K. pneumoniae isolate B6 using a scanning electron microscope revealed morphologic changes in the cell surface after treatment with each antibiotic both alone and in combination. The whole genome of $K$. pneumoniae KPNB1 was sequenced using an lon Torrent PGM sequencer.

Results: According to the checkboard results, synergistic combinations were observed with ertapenem/meropenem (5/10 isolates), meropenem/colistin (7/10) and ertapenem/meropenem/colistin (9/10); no antagonism was observed for all combinations. For the time-kill assay results; synergism and bactericidal effects were observed with meropenem/ colistin (10/10) and with ertapenem/meropenem/colistin (10/10) combinations, and an indifference effect was observed with the ertapenem and meropenem (10/10) combination. Strain number 1 was found 100\% identical to Klebsiella pneumoniae subsp. pneumoniae HS11286 according to the outcomes of complete genome sequence analysis, and the strain carried the genes bla $\mathrm{OXA}_{-181}$, bla $\mathrm{a}_{\mathrm{CTM}-15}$, blaNDM, arr-3, aac (6')-lb-cr, rmtF, and catB1.

Conclusion: Using double carbapenem antibiotics with colistin could be a potential alternative to treat colistin and carbapenem-resistant $K$. pneumoniae. The present study is the first Turkish report of OXA-181-type carbapenemase causing colistin resistance.
\end{abstract}

Keywords: Colistin-resistant Klebsiella pneumoniae, Time-kill assay, OXA-181, OXA-48, NDM, Whole genome analysis, PCR-based replicon typing, PFGE, MLST

\footnotetext{
* Correspondence: dr.akfatma@hotmail.com

'Department of Medical Microbiology, Adana City Trainning and Research Hospital, Dr. Mithat Ozsan Boulevard. 4522-1 Yuregir/Adana, Adana, Turkey

Full list of author information is available at the end of the article
}

C C The Author(s). 2020 Open Access This article is licensed under a Creative Commons Attribution 4.0 International License, which permits use, sharing, adaptation, distribution and reproduction in any medium or format, as long as you give appropriate credit to the original author(s) and the source, provide a link to the Creative Commons licence, and indicate if changes were made. The images or other third party material in this article are included in the article's Creative Commons licence, unless indicated otherwise in a credit line to the material. If material is not included in the article's Creative Commons licence and your intended use is not permitted by statutory regulation or exceeds the permitted use, you will need to obtain permission directly from the copyright holder. To view a copy of this licence, visit http://creativecommons.org/licenses/by/4.0/ The Creative Commons Public Domain Dedication waiver (http://creativecommons.org/publicdomain/zero/1.0/) applies to the data made available in this article, unless otherwise stated in a credit line to the data. 


\section{Introduction}

Infections due to multiple drug-resistant (MDR) Gramnegative bacteria have seriously increased worldwide. Carbapenems and colistin have been the treatment of choice for serious infections due to MDR gram negative rods but unfortunately resistance to carbapenems and colistin compromise the treatment options [1]. K. pneumoniae strains show high levels of resistance to carbapenems and other antimicrobial classes, with increasing reports of colistin resistance [2, 3]. Colistin resistance in Klebsiella pneumoniae is related to modifications of lipopolysaccharide (LPS) by the addition of cationic charges, which decreases the affinity of polymyxins to the LPS target. The modification of LPS is mediated by the pmrHFIJKLM operon, regulated by the PhoPQ and PmrAB two-component systems. A small transmembrane protein $\mathrm{MgrB}$ negatively regulates the PhoPQ system by interaction with the sensor kinase PhoQ in the periplasmic domain, preventing activation of the pmrHFIJKLM operon $[4,5]$. Other limitations of colistin treatment are toxicity and adverse effects [6]. The toxicity of colistin is considered to be dose-dependent and dose can be decreased by using colistin in a combination [7].

Ceftazidime/avibactam or ceftolozane/tazobactam like regimens are the other treatment options for the pandrugresistant K.pneumoniae strains. Avibactam is a synthetic non- $\beta$-lactam $\beta$-lactamase inhibitor that inhibits the activities of Ambler class A and C- $\beta$ lactamases and some Ambler class D enzymes, including bla ${ }_{K P C}$ carbapenemases, AmpC, and OXA-48-like carbapenemases, respectively. However, it does not inhibit metallo- $\beta$-lactamases, such as bla $_{\text {VIM }}$ or bla $_{\text {NDM }}$ variants [8]. Otherwise, avibactam protects aztreonam from hydrolysis by $\beta$-lactamases. So, when aztreonam is combined with avibactam, a synergistic effect occurs against bla $\mathrm{NDM}_{\mathrm{ND}}$-producing Enterobacteriaceae [9]. On the other hand, ceftazidime avibactam was combined with either amikacin or meropenem against four KPCproducing K. pneumoniae. Synergistic effects were observed in vitro in time-kill assays and increased survival rates were observed in an in vivo model with these combinations [10].

Combinations of different antimicrobials against MDR $K$. pneumoniae isolates were investigated by others. Elamam et al. tested two-drug combinations of antimicrobials against 12 polymyxin B-resistant $K$. pneumoniae isolates. Synergistic effects were observed with polymyxin B- rifampin, doxycycline-polymyxin B, and tigecyclinepolymyxin $\mathrm{B}$, but no interaction was observed with a polymyxin B-gentamicin combination $[11,12]$. Furthermore, in another study, a synergistic effect was determined with ertapenem and meropenem combinations against both bla $_{\text {KPC }}$ and bla OXA-48 producers, but not with bla ${ }_{\text {NDM }}$ producers [13]. Combination with imipenem is an alternative option. However, poor activity was observed with imipenem against bla $\mathrm{OXA}_{48}$-producing isolates in invivo experiments $[14,15]$.
New therapeutic approaches are needed because pandrug-resistant Klebsiella pneumoniae strains have been increasingly reported worldwide. Combination antibiotic therapy is an efficient approach to treating these infections. Synergy tests might be useful in selecting the best antimicrobial combination for infections due to MDR and PDR Klebsiella pneumoniae [16]. We aimed to evaluate the activities of ertapenem and meropenem (ERT/MEM), meropenem and colistin (MEM/COL), ertapenem, meropenem and colistin (ERT/MEM/COL) combinations against 10 colistin-resistant $K$. pneumoniae clinical isolates harboring different $\beta$-lactamases (bla $\mathrm{OXA}-48, \mathrm{bla}_{\mathrm{NDM}}$ [14]).

\section{Materials and methods}

Strain collection and antimicrobial susceptibility tests

A collection of 10 MDR and bla $a_{\text {OXA-48 }}$ and/or bla ${ }_{\text {NDM }}$ carbapenemase-producing $K$. pneumoniae clinical isolates were studied because a few MDR $K$. pneumoniae strains have been isolated in our hospital since 2016. The isolates were obtained from clinical samples of hospitalized patients. Antimicrobial susceptibility and MIC characterization was performed using gradient tests. For ertapenem, meropenem, imipenem and colistin, MICs were determined using broth microdilution method. Susceptibility results were interpreted according to the Clinical Laboratory Standards Institute (CLSI) clinical breakpoint guidelines [17]. Beta lactamase activity of isolates was investigated using the disk diffusion test, E test, Blue-Carba (BCT), and Modified Hodge test (MHT).

\section{Synergy tests}

Ertapenem/meropenem (ERT/MEM), meropenem/colistin (MEM/COL) and ertapenem/meropenem/colistin (ERT/MEM/COL) combinations were tested using the checkerboard technique and time-kill assays, with each antibiotic alone and in combinations.

\section{Checkerboard technique}

The overnight cultures (initial inoculum of $10^{5}-10^{6}$ $\mathrm{CFU} / \mathrm{mL}$ ) were performed with ERT, MEM, and COL alone as well as in combinations. For each strain and antibiotic, the selected concentration ranges were based on the (minimum inhibitory concentrations) MICs of antibiotics. Five increasing (4-fold) concentrations $(0.125 \times \mathrm{MIC}$ to $2 \times \mathrm{MIC})$ were used, Interpretation of the checkerboard results was based on the following: fractional inhibitory concentration (FIC) values of $\leq 0.5$ indicate synergy, FIC values of 0.5 to 4 indicate no interaction, and FIC values of $>4$ indicate antagonism. The reduction of the original inoculum by $\geq 3 \log _{10} \mathrm{CFU} / \mathrm{mL}$ was considered bactericidal and a reduction of $\geq 2 \log _{10}$ $\mathrm{CFU} / \mathrm{mL}$ by the antibiotic combination compared with that of the most active compound was defined as synergism. Indifference was defined as $a \leq 1 \log _{10}$ reduction 
with the combination compared with that obtained with the most active single agent [18].

\section{Time-kill assays}

Overnight cultures (initial inoculum of $10^{5}-10^{6} \mathrm{CFU} /$ $\mathrm{mL}$ ) were performed with ERT, MEM, and COL alone as well as in combinations. ERT, MEM, and COL corresponding Cmax serum concentrations $(\mu \mathrm{g} / \mathrm{mL}) 150,40$, and 10 , respectively, were used in all experiments. In vitro activity was assessed at $1,2,4,6,8$, and $24 \mathrm{~h}$. The effect of colistin and its association were also assessed at $30 \mathrm{~min}$ [19].

\section{Scanning electron microscope (SEM)}

Morphologic changes; An analysis of K. pneumoniae isolate B6 using an SEM revealed morphologic changes on the cell surface after treatment with each antibiotic both alone and in combination.

Overnight cultures (initial inoculum of $10^{5}-10^{6} \mathrm{CFU} /$ $\mathrm{mL}$ ) were performed with ERT, MEM, and COL alone as well as in combinations. ERT, MEM and COL corresponding Cmax serum concentrations 150, 40 and $10 \mu \mathrm{g} / \mathrm{mL}$, respectively, were used and in vitro activity was assessed at $1 \mathrm{~h}$. The tubes were incubated at $37^{\circ} \mathrm{C}$ in a shaking water bath for $1 \mathrm{~h}$ and then centrifuged at $3220 \mathrm{~g}$ for $10 \mathrm{~min}$. The bacterial cells were fixed with $2.5 \%$ glutaraldehyde before being washed and resuspended three times in PBS. The bacterial cultures were incubated on polyethylenimine-coated coverslips (22 $\mathrm{mm} \times 22 \mathrm{~mm}$ ) for $1 \mathrm{~h}$ and immersed for a further hour in 2.5\% glutaraldehyde in PBS before rinsing in PBS for $10 \mathrm{~min}$, three times. Dehydration was then performed using increasing concentrations of ethanol in water $(10$, 30, 50, 70, 90 and 100\%) for $10 \mathrm{~min}$ in each step. The coverslips were air-dried prior to mounting on $25-\mathrm{mm}$ aluminum stubs with double-sided carbon tabs. Silver liquid was applied to the edges of each coverslip, and these were then dried and gold coated in an SC7620 sputter coater (QUORUM TECHNOLOGIES, Ashford Kent, UK). The cells were imaged by using a Quanta FEG 450 SEM (FEI, Hillsboro, OR, USA) [20].

\section{PFGE (pulse-field gel electrophoresis) and MLST (multi- locus sequence typing)}

Genomic DNA was prepared in agarose blocks and digested with the restriction enzyme XbaI. The DNA fragments were separated for $20 \mathrm{~h}$ at $6 \mathrm{~V} / \mathrm{cm}$ and $14{ }^{\circ} \mathrm{C}$ with initial and final pulse times of 0.5 and $30 \mathrm{~s}$, respectively [21]. Multi-locus sequence typing (MLST) of K. pneumoniae was performed as described by Diancourt et al. [22]. DNA sequences were uploaded into the MLST database (http://bigsdb.web.pasteur.fr/klebsi ella/klebsiella.html) and allelic numbers and sequence types (STs) were obtained.

\section{Genotypic detection of resistance genes}

PCR (Polymerase Chain Reaction) and sequencing was used to screen for the presence of genes encoding for colistin (pmrA, pmrB, phoP, phoQ, and mgrB); Class A (bla $\left.\mathrm{KPC}_{\mathrm{KPC}}, \mathrm{bla}_{\mathrm{GES}}\right)$, Class D (bla $\mathrm{OXA}_{-48}, \mathrm{bla}_{\mathrm{OXA}-181}$ ) and Class $\mathrm{B}\left(\mathrm{bla}_{\mathrm{NDM}}, \mathrm{bla}_{\mathrm{IMP}}, \mathrm{bla}_{\mathrm{VIM}}, \mathrm{bla}_{\mathrm{SPM}}, \mathrm{bla}_{\mathrm{SIM}}\right)$ carbapenemases and ESBL (bla ${ }_{\text {CTX-M }}$, bla ${ }_{\text {TEM }}$, bla SHV $_{\text {}}$ ) $[23,24]$. In addition, plasmid-borne $16 \mathrm{~S}$ rRNA methylases, including $\operatorname{arm} A, \operatorname{rmt}(\mathrm{A}-\mathrm{E}), n p m A$; plasmid-borne quinolone genes (qnrA, qurB, qurS, qepA, aac (6')-Ib-cr) and AmpC beta lactamases genes (DHA, ACC, FOX, MOX, CIT AND $E B C)$ were screened [24-27]. The results were confirmed by sequencing.

\section{Whole-genome sequencing (WGS)}

In order to determine the genetic basis of pandrugresistance, we interrogated the genome to identify acquired and intrinsic resistance genes. Chromosomal and plasmid genomes were sequenced using an Ion Torrent PGM sequencer (Thermo Scientific, Bremen, Germany), with 316 v2 chip sequencing, generating 100 base-paired end reads [28].

\section{Plasmid typing}

Plasmid typing analysis was performed using multiplex PCR-based replicon typing (HI1, HI2, I1, I2, X1, X2, L/ $\mathrm{M}, \mathrm{N}$, FIA, FIB, FIC, FII, FIIS, FIIK, W, Y, P, A/C, T, K, U, R, B/O, HIB-M), as described by Caratolli et al. [29].

\section{Results}

All strains were resistant to all tested antibiotics except tigecycline and amikacin (5/10), and all NDM-1-producer isolates were resistant to amikacin. They were resistant to doripenem (MICs ranging from 4 to $32 \mathrm{mg} / \mathrm{L}$ ), ertapenem (64 to $>128 \mathrm{mg} / \mathrm{L}$ ), and meropenem (16 to $128 \mathrm{mg} / \mathrm{L}$ ), colistin (4 to $64 \mathrm{mg} / \mathrm{L}$ ) (Tables 1 and 2).

According to the checkerboard results; in vitro synergistic activities were observed with ertapenem/meropenem (5/10 isolates), meropenem/colistin (7/10) and ertapenem/meropenem/colistin (9/10); no antagonism was observed for all combinations. For the time-kill assay results; synergism and bactericidal effects were observed with meropenem/colistin and with ertapenem/ meropenem/colistin combinations (10/10), and an indifference effect was observed with the ertapenem and meropenem combination (10/10) (Table 2).

Analysis of K. pneumoniae isolate B6 with SEM revealed morphologic changes on the cell surface after treatment with each antibiotic both alone and in combinations and in the absence of antibiotics. The cell surface in the control group was smooth, whereas the cells treated with ertapenem, meropenem, and colistin alone showed uneven surface bulges (Fig. 1). The combination treatment with meropenem/colistin, ertapenem/meropenem and especially ertapenem/meropenem/colistin combinations caused more 
Table $1 \mathrm{MICs}$ (mg/L) of antibiotics against K pneumoniae strains

\begin{tabular}{lllllllllllllll}
\hline & TGC & OF & AMC & LEV & DOR & PTC & AK & CIP & CRO & CXM & TZ/TZL & IP/IPL & TOB & $C T / C T L$ \\
\hline $\mathbf{1}$ & 3 & $>32$ & 128 & $>32$ & $>32$ & $>256$ & $>256$ & 16 & $>32$ & $>256$ & $>32 />4$ & $<4 /<1$ & 192 & $>16 />1$ \\
$\mathbf{2}$ & 0.38 & $>32$ & $>32$ & $>32$ & $>32$ & $>256$ & 4 & $>32$ & $>32$ & $>256$ & $>32 />4$ & $<4 / 1.5$ & 24 & $>16 />1$ \\
$\mathbf{1 4}$ & 0.50 & $>32$ & $>256$ & $>32$ & 4 & $>256$ & 12 & $>32$ & $>256$ & $>256$ & $>32 />4$ & $4 / 0.5$ & 24 & $>16 />1$ \\
$\mathbf{2 1}$ & 05 & $>32$ & $>256$ & $>32$ & 4 & $>256$ & 8 & $>32$ & $>32$ & $>256$ & $>32 />4$ & $<4 / 1.5$ & 24 & $>16 />1$ \\
$\mathbf{2 2}$ & 1 & $>32$ & $>256$ & 32 & $>32$ & $>256$ & $>256$ & $>32$ & $>32$ & $>256$ & $>32 />4$ & $<4 /<1$ & $>1024$ & $>16 />1$ \\
$\mathbf{2 4}$ & 0.50 & $>32$ & $>256$ & 32 & $>32$ & $>256$ & 6 & $>32$ & $>32$ & $>256$ & $>32 />4$ & $4 / 1.5$ & 24 & $>16 />1$ \\
$\mathbf{2 8}$ & 0.38 & $>32$ & $>256$ & $>32$ & 4 & $>256$ & 4 & $>32$ & $>32$ & $>256$ & $>32 />4$ & $<4 / 1$ & 32 & $>16 />1$ \\
$\mathbf{3 1}$ & 2 & 32 & $>256$ & $>32$ & 6 & $>256$ & 8 & $>32$ & $>32$ & $>256$ & $>32 />4$ & $<4 / 2$ & 32 & $>16 />1$ \\
$\mathbf{3 7}$ & 0.50 & $>32$ & $>256$ & $>32$ & 4 & $>256$ & $>256$ & $>32$ & $>32$ & $>256$ & $>32 />4$ & $<4 /<1$ & $>1024$ & $>16 />1$ \\
$\mathbf{B 6}$ & 0.38 & $>32$ & $>256$ & $>32$ & 12 & $>256$ & $>256$ & $>32$ & $>32$ & $>256$ & $>32 />4$ & $<4 /<1$ & 192 & $>16 />1$
\end{tabular}

TGC Tigecycline, OF Ofloxacin, AMC Amoksicilin clavulonik acid, LEV Levofloxacin, CIP Ciprofloxacin, CRO Ceftriaksone, CXM Cefuroxime, TZ/TZL Tikarcilin/tikarcilin clavulonic acid, IP/IPL Imipenem/Imipenem EDTA, TOB Tobramycin, CT/CTL Cefotaxime/ cefotaxime clavulonic acid

significant damage to the cell surface, with numerous bulges and roughness and enlargement in the central region of their walls and cellular lysis. The cells had filaments in the central region of their cytoplasms. The filament formations in our results appeared as lightened areas in the midregion of the bacterial cells. K. pneumoniae cells showed the development of numerous breaks in the cell wall, suggesting that the primary target of this treatment was the outer membrane of these Gram-negative bacteria (Fig. 1). Treatment was disrupting the outer membrane and cell wall and this led to the death of the cells [20].

PFGE analysis of the 10 isolates revealed the existence of five different genetic clusters (Fig. 2: a-e). Four sequence types were obtained through MLST (ST14( $n=$ $1), \operatorname{ST} 15(n=1), \operatorname{ST} 101(n=6), \operatorname{ST} 395(n=2))$ (Table 2).

All of the isolates were positive for bla ${ }_{\mathrm{CTXM}-15}$, bla $\mathrm{SHV}_{\mathrm{SH}}$ beta lactamases. Eight of the isolates also coproduced bla $_{\text {TEM }}$ beta lactamase. All isolates produced at least one of the two main types of carbapenemases: bla OXA-48 $_{2}(n=$ 8 ), and bla NDM-1 $_{1}(n=3)$, one isolate co-produced two carbapenemases, bla $\mathrm{OXX}_{-48}$ and $\mathrm{bla}_{\mathrm{NDM}-1}$. Isolate 37 was carrying QnrB, isolate B6 was carrying QnrS and CIT genes. For all isolates, at least one aminoglycoside resistance-associated gene was detected $(\operatorname{RmtB}(n=1)$, $r m t D(n=5), \operatorname{rmtC}(n=3))$ (Table 2).

Regarding the plasmid types, eight isolates possessed an Inc./rep of type $\mathrm{R}$ and $\mathrm{L}$. One isolate that expressed bla $_{\mathrm{NDM}-1}$ hosted an Inc./rep of type R, H1B-M, F1B and FII, a second isolate that expressed blaNDM-1 possessed an Inc./rep of type R and A/C (Table 2).

\section{Whole-genome sequencing of $K$. pneumoniae 1 (KPNB1)} WGS was done for KPNB1 that was found to be nonsusceptible to all antibiotics tested, including tigecycline, cephalosporins, penicillins, carbapenems, aztreonam, aminoglycosides, quinolones, colistin, and tetracycline. The complete genome of KPNB1 consists of a circular chromosome 5,533,942 base-pairs in length. It was found $100 \%$ identical to Klebsiella pneumoniae subsp. pneumoniae HS11286 isolated from human sputum in 2011 in Shanghai, China according to the outcomes of complete genome sequence analysis [30]. Three copies of bla OXA-181

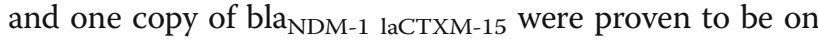
ISEcp1. One ISEcp1-bla OXA-181 mobile element had disrupted the $\operatorname{mgr} B$ regulatory gene, accounting for resistance to colistin, and the strain carried the genes bla ${ }_{\text {OXA-181 }}$, $\mathrm{bla}_{\mathrm{CTXM}-15}, \mathrm{bla}_{\mathrm{NDM}}$, arr-3, aac (6')-Ib-cr, rmtF and catB1. The complete genome of the plasmid that codes

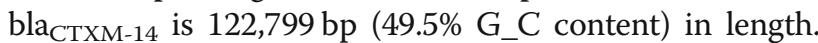
The outcomes of the study showed that an blaNDM-type carbapenemase gene was carried on the plasmid. Outcomes of MLST analysis revealed that the strain was an ST14 sequence-type isolate.

\section{Discussion}

Global spread of MDR K. pneumoniae is an epidemiologic challenge. Accurate treatment, along with infection control measures all have a role in preventing the development of resistant strains. Reduced mortality is associated with appropriate antimicrobial therapy and with the initiation of this therapy in the early stage of infection [31].

In this study, by the checkerboard tests, synergistic effects were observed for all drug combinations aganist three NDM-producing isolates. Additive effects were observed with ertapenem-meropenem and meropenem-colistin combinations against one $\mathrm{bla}_{\text {NDM }}$ producer which has CTXM15, TEM, SHV, CIT, rmtB-C, QnrS resistance genes. While variable effects were observed with double carbapenem, synergistic effects were observed with triple combination against eight bla OXA-48 $_{2}$ producing K.pneumoniae strains. According to time kill studies synergistic effects were observed with both meropenem-colistin and ertapenemmeropenem-colistin combinations against both $\mathrm{bla}_{\mathrm{NDM}}$ and bla $_{\text {OXA-48 }}$ producers. A indifference effects were observed 


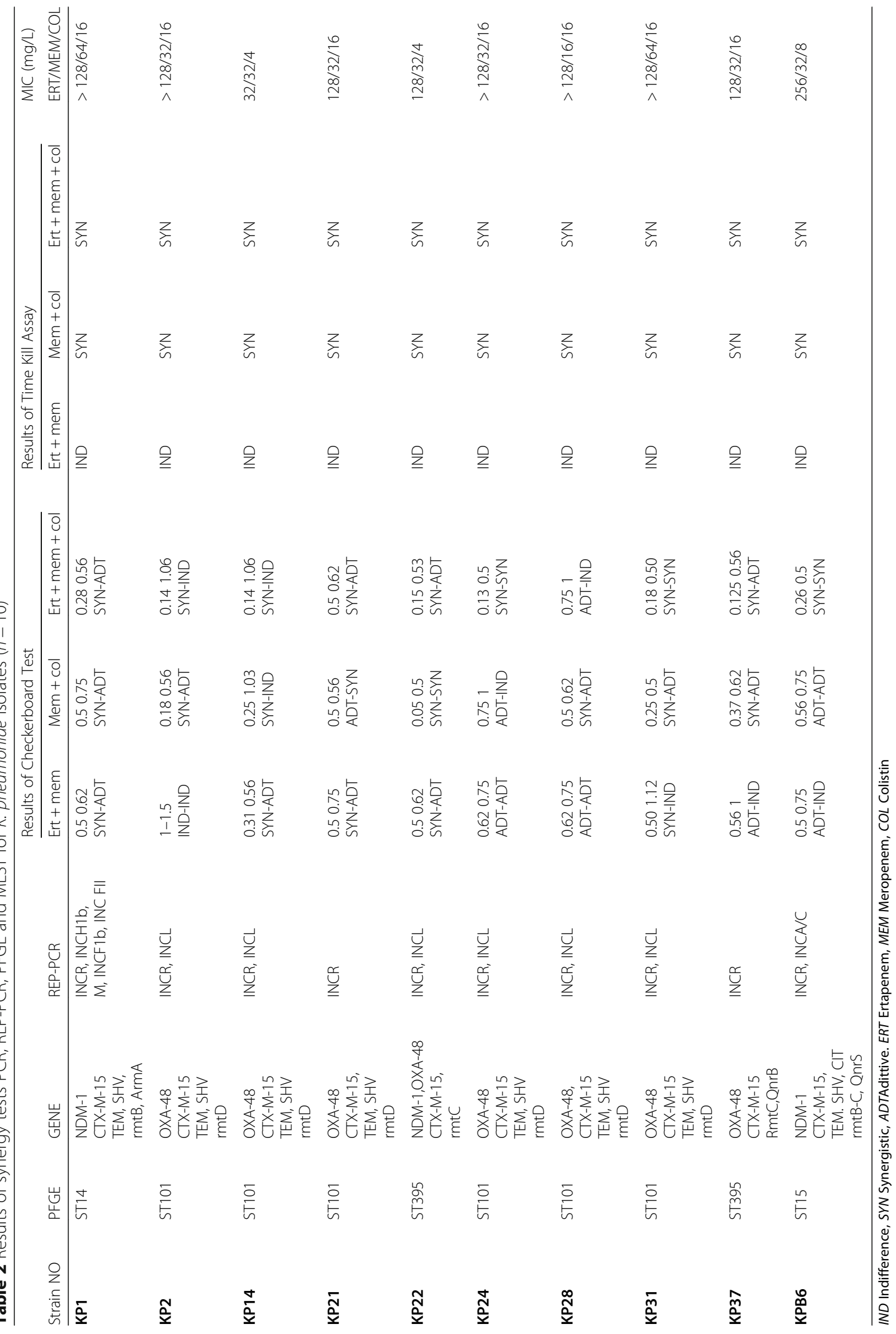




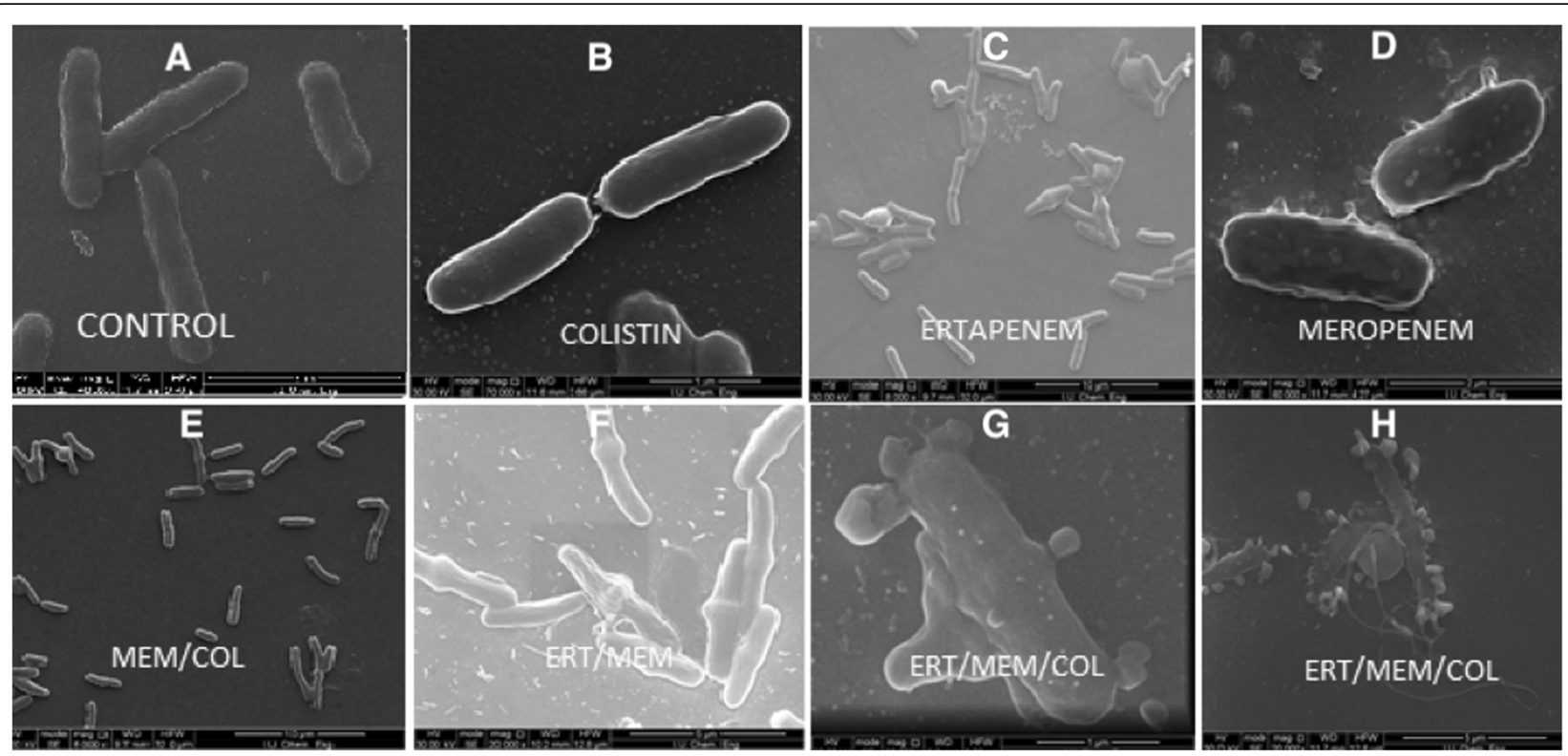

Fig. 1 a. SEM images of K. pneumoniae B6. b. Control (absance of drug therapy): Smooth cell surface. c. Precense of colistin: Minimal pits and protrusions. on the cell surface. $\mathbf{d}$. Precense of ertapenem: Minimal pits and protrusions. e. Precense of meropenem: Minimal pits and protrusions f. Precense of meropenem and colistin: Minimal pits and protrusions..g. Precense of ertapenem, meropenem: Minimal pits and cantral bulginess. h. Precense of ertapenem, meropenem and colistin: Severe cell membrane demage and celuler lysis. ERT:Ertapenem,

MEM:Meropenem, COL:Colistin

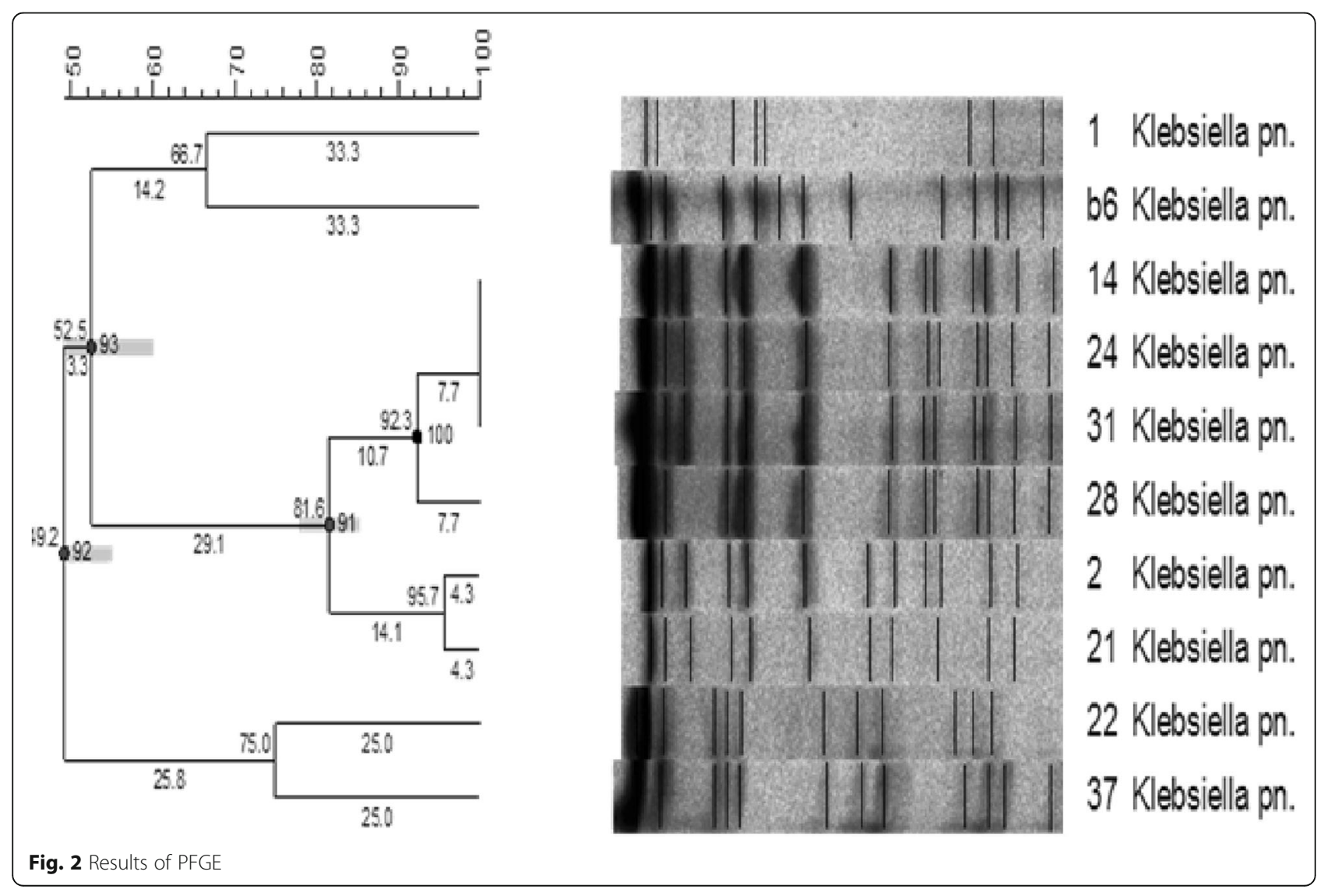


with ertapenem-meropenem against both $\mathrm{bla}_{\mathrm{NDM}}$ and bla OXA-48 producing K.pneumoniae strains (Table 2).

In this study, regimens of colistin combined with one or two carbapenem exhibited a high level of synergism, even in the presence of colistin resistance. The results were in agreement with other studies that investigated effect of triple (Ertapenem plus meropenem plus colistin) and double combinations (meropenem plus colistin) [32, 33].

In several studies, the use of double carbapenem regimen has been proposed as a valid therapeutic option in the treatment of KPC producing, multi-drug resistant Klebsiella pneumoniae clinical isolates [34-36]. On the other hand, in a study, bactericidal activity was reported from 17 to $20 \%$ with double combinations of ertapenem, meropenem and imipenem against OXA-48-producing Klebsiella pneumoniae clinical isolates. In the same study, no combination axhibited antagonism [37].

In this study, different sequence types with bla $_{\mathrm{NDM}^{-}}$ positive isolates obtained with MLST and PFGE results indicate different geographic origins and horizontal transfer of resistance elements. Over 50\% of NDMproducing $K$. pneumoniae isolates were reported from India belonging to either ST11 or ST147 [38]. ST14, ST101, and ST395 have been reported in European countries. K. pneumoniae ST14-coproducing blaNDM1 was reported in India, the United Kingdom, Sweden, and the United Arab Emirates [39, 40] ST15 K. pneumoniae isolates were reported in Bulgaria, Croatia, Czech Republic, Denmark, Hungary, Italy, The Netherlands, and Spain, China, South Korea, Malaysia, Singapore, Thailand, and Vietnam [41]. However, it is noteworthy that, this study was presented at the 26th European Congress of Clinical Microbiology and Infectious Diseases (ECCMID 2016. (EPO234) as the first report of ST 15 NDMproducing $K$. pneumoniae [42, 43].

This study confirmed that acquisition and spread of resistance genes are associated with mobile genetic elements such as plasmids and transposons. The bla $\mathrm{NDM}_{\mathrm{ND}}$ and bla OXA-48 genes are carried on plasmids, and spread by transferable elements between diferent plasmids, and is then further spread in multiple bacteria via plasmids. The results obtained in this study showed that all isolates are expressed Inc. $\mathrm{R}$ type plasmid corelated with the previous study which was conducted with carbapenem resistant Klebsiella pneumoniae strains [44]. Also, inc L is the second most common plasmid type (9/ 10) which was previously shown to be responsible for transfer of bla OXA-48 type carbapenemase in a ST395 K.pneumoniae strain [44, 45]. One isolate that expressed bla $_{\text {NDM-1 }}$ and bla $\mathrm{CTX}_{\mathrm{CT}-15}$ hosted an Inc./rep type of R, H1B-M, F1B and FII. IncFIIK plasmids, which are important vehicles of multiple antibiotic resistance genes, have been shown to be resposible for transferring bla $_{\mathrm{CTxM}-15}$ and other resistant genes [46]. Otherwise, molecular epidemiologic studies have reported that IncA/C, IncFIIK, IncL/M, and IncH1 type plasmids are responsible for the horizontal spread of blaNDM-type carbapenemase [47, 48]. Also, the IncX3-type plasmid has been reported to be responsible for horizontal trans-

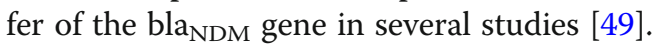

In this study, it was shown that genes encoding $16 \mathrm{~S}$ rRNA methyltransferase were accompanied by the $\beta$ lactamase enzymes (10/10). Otherwise, co-existence of the blaNDM-1 and $r m t C$ genes was reported in Turkey in 2016 coraleted with this study [50]. However, it has been shown that genes encoding 16S rRNA methyltransferase and $\beta$-lactamase enzymes are usually transported by the same plasmid. So this situation allows for considerable effectiveness of aminoglycosides in combination with carbapenems or colistin [51].

The present study is the first Turkish report of blaOXA-181-type carbapenemase causing colistin resistance. blaOXA-181 differs from blaOXA-48 by four amino 80 acid substitutions. Inactivation of $m g r B$ has recently been associated with resistance to colistin, and appears to be the most common mechanism for polymyxin resistance in K. pneumoniae [52] and it is interesting to note that $m g r B$ is disrupted by a functional, ISEcp1-driven blaOXA-181 insertion causing resistance to carbapenems [53, 54]. The emergence of colistin resistance in blaOXA181-producing $K$. pneumoniae has been reported worldwide, which was first reported in 2011 from India [53]. It was reported as the most common carbapenemase followed by blaOXA-48 in Canada between 2011 and 2014 [55-57].

\section{Conclusion}

The ERT/MEM/COL combination was demonstrated to be synergistic and bactericidal. Using double carbapenem antibiotics with colistin further increased the synergistic effect in MDR Klebsiella pneumonia strains. This combination might prevent resistance development and secondary effects of colistin monotherapy. Our data could be helpful for clinicians to treat patients with COL-resistant CRKP infections. Our findings suggest that; in vitro synergy tests should be routinely performed in cases of infections due to COL-resistant CRKP strains to select the best antimicrobial combinations. Furthermore, there is a need for long-term multi-centered molecular epidemiologic studies for the recognition of the global spread of antibiotic resistance.

\section{Acknowledgements \\ Not applicable.}

Authors' contributions

$\mathrm{OO}$ and $\mathrm{ZA}$ directcd and designed the study. FE and AA carried out in vitro studies (time kill assay, checkerboard technique) and the molecular genetic studies MLST, PFGE, WGS). FE drafted the manuscript with ZA. O. O 
conceived and supervised the project. Led the final assembly of the manuscript. The author(s) read and approved the final manuscript

\section{Funding}

No specific funding has been received.

\section{Availability of data and materials}

Not applicable.

\section{Ethics approval and consent to participate}

Not applicable.

\section{Consent for publication}

Not applicable.

\section{Competing interests}

The authors declare that they have no competing interests.

\section{Author details}

'Department of Medical Microbiology, Adana City Trainning and Research Hospital, Dr. Mithat Ozsan Boulevard. 4522-1 Yuregir/Adana, Adana, Turkey. ${ }^{2}$ Department of Medical Microbiology, Istanbul University Istanbul Medical Faculty, Istanbul, Turkey. ${ }^{3}$ Department of Infection Disease and Clinical Microbiology, Istanbul University Istanbul Medical Faculty, Istanbul, Turkey.

\section{Received: 6 December 2019 Accepted: 5 May 2020}

\section{Published online: 19 May 2020}

\section{References}

1. Rahal JJ. The role of carbapenems in initial therapy for serious Gramnegative infections. Crit Care. 2008;12(Suppl 4):S5. https://doi.org/10.1186/ cc6821.

2. Liu YY, Wang Y, Walsh TR, Yi LX, Zhang R, Spencer J, et al. Emergence of plasmid-mediated colistin resistance mechanism MCR-1 in animals and human beings in China: a microbiological and molecular biological study. Lancet Infect Dis. 2016;16(2):161-8. https://doi.org/10.1016/s14733099(15)00424-7.

3. Kieffer N, Poirel L, Nordmann P, Madec JY, Haenni M. Emergence of colistin resistance in Klebsiella pneumoniae from veterinary medicine. J Antimicrob Chemother. 2015;70(4):1265-7. https://doi.org/10.1093/jac/dku485.

4. Cannatelli A, D'Andrea MM, Giani T, Di Pilato V, Arena F, Ambretti S, et al. In vivo emergence of colistin resistance in Klebsiella pneumoniae producing KPC-type carbapenemases mediated by insertional inactivation of the PhoQ/PhoP mgrB regulator. Antimicrob Agents Chemother. 2013;57(11): 5521-6. https://doi.org/10.1128/aac.01480-13.

5. Stoesser N, Mathers AJ, Moore CE, Day NP, Crook DW. Colistin resistance gene mcr-1 and pHNSHP45 plasmid in human isolates of Escherichia coli and Klebsiella pneumoniae. Lancet Infect Dis. 2016;16(3):285-6. https://doi. org/10.1016/s1473-3099(16)00010-4.

6. Sahbudak Bal Z, Kamit Can F, Yazici P, Berna Anil A, Duyu M, Yilmaz Ciftdogan D, et al. The evaluation of safety and efficacy of colistin use in pediatric intensive care unit: Results from two reference hospitals and review of literature. J Infect Chemother. 2018;24(5):370-5. https://doi.org/10. 1016/j.jiac.2017.12.017

7. Falagas ME, Kasiakou SK. Colistin: the revival of polymyxins for the management of multidrug-resistant gram-negative bacterial infections. Clin Infect Dis. 2005;40(9):1333-41.10.1086/429323.

8. Mushtaq S, Warner M, Williams G, Critchley I, Livermore DM. Activity of chequerboard combinations of ceftaroline and NXL104 versus betalactamase-producing Enterobacteriaceae. J Antimicrob Chemother. 2010; 65(7):1428-32. https://doi.org/10.1093/jac/dkq161.

9. Sy SK, Beaudoin ME, Zhuang L, Loblein Kl, Lux C, Kissel M, et al. In vitro pharmacokinetics/pharmacodynamics of the combination of avibactam and aztreonam against MDR organisms. J Antimicrob Chemother. 2016;71(7): 1866-80. https://doi.org/10.1093/jac/dkw082.

10. Nath S, Moussavi F, Abraham D, Landman D, Quale J. In vitro and in vivo activity of single and dual antimicrobial agents against KPC-producing Klebsiella pneumoniae. J Antimicrob Chemother. 2018;73(2):431-6. https:// doi.org/10.1093/jac/dkx419.

11. Bratu S, Tolaney P, Karumudi U, Quale J, Mooty M, Nichani S, et al. Carbapenemase-producing Klebsiella pneumoniae in Brooklyn, NY: molecular epidemiology and in vitro activity of polymyxin B and other agents. J Antimicrob Chemother. 2005;56(1):128-32. https://doi.org/10. 1093/jac/dki175.

12. Elemam A, Rahimian J, Doymaz M. In vitro evaluation of antibiotic synergy for polymyxin B-resistant carbapenemase-producing Klebsiella pneumoniae. J Clin Microbiol. 2010;48(10):3558-62. https://doi.org/10.1128/jcm.01106-10.

13. Poirel L, Kieffer N, Nordmann P. In vitro evaluation of dual carbapenem combinations against carbapenemase-producing Enterobacteriaceae. J Antimicrob Chemother. 2016;71(1):156-61. https://doi.org/10.1093/jac/ dkv294.

14. Wiskirchen DE, Nordmann P, Crandon JL, Nicolau DP. Efficacy of humanized carbapenem and ceftazidime regimens against Enterobacteriaceae producing OXA-48 carbapenemase in a murine infection model. Antimicrob Agents Chemother. 2014;58(3):1678-83. https://doi.org/10.1128/aac.01947-13.

15. Mimoz O, Gregoire N, Poirel L, Marliat M, Couet W, Nordmann P. Broadspectrum beta-lactam antibiotics for treating experimental peritonitis in mice due to Klebsiella pneumoniae producing the carbapenemase OXA-48. Antimicrob Agents Chemother. 2012;56(5):2759-60. https://doi.org/10.1128/ aac.06069-11.

16. Galani I, Nafplioti K, Chatzikonstantinou M, Souli M. In vitro evaluation of double-carbapenem combinations against OXA-48-producing Klebsiella pneumoniae isolates using time-kill studies. J Med Microbiol. 2018. https:// doi.org/10.1099/jmm.0.000725.

17. The Clinical \& Laboratory Standards Institute (CLSI) supplement M100 (ISBN 978-1-68440-032-4 [Print]; ISBN 978-1-68440-033-1 ... Wayne P. 2019 29th Edition.

18. National Committee for Clinical Laboratory Standards. Methods for Determining Bactericidal Activity of Antimicrobial Agents-Approved Standard M26-A. Wayne P, USA: NCCLS; 1999.

19. Diez-Aguilar M, Morosini MI, Tedim AP, Rodriguez I, Aktas Z, Canton R Antimicrobial activity of fosfomycin-tobramycin combination against Pseudomonas aeruginosa isolates assessed by time-kill assays and mutant prevention concentrations. Antimicrob Agents Chemother. 2015;59(10): 6039-45. https://doi.org/10.1128/aac.00822-15.

20. Abdul Rahim N, Cheah SE, Johnson MD, Yu H, Sidjabat HE, Boyce J, et al. Synergistic killing of NDM-producing MDR Klebsiella pneumoniae by two 'old' antibiotics-polymyxin B and chloramphenicol. J Antimicrob Chemother. 2015;70(9):2589-97. https://doi.org/10.1093/jac/dkv135.

21. Aktas Z, Day M, Kayacan CB, Diren S, Threlfall EJ. Molecular characterization of Salmonella Typhimurium and Salmonella Enteritidis by plasmid analysis and pulsed-field gel electrophoresis. Int J Antimicrob Agents. 2007;30(6):541-5.

22. Diancourt L, Passet V, Verhoef J, Grimont PA, Brisse S. Multilocus sequence typing of Klebsiella pneumoniae nosocomial isolates. J Clin Microbiol. 2005 43(8):4178-82. https://doi.org/10.1128/jcm.43.8.4178-4182.2005.

23. Jayol A, Poirel L, Villegas MV, Nordmann P. Modulation of mgrB gene expression as a source of colistin resistance in Klebsiella oxytoca. Int J Antimicrob Agents. 2015;46(1):108-10. https://doi.org/10.1016/j.ijantimicag. 2015.02.015.

24. Perez-Perez FJ, Hanson ND. Detection of plasmid-mediated AmpC betalactamase genes in clinical isolates by using multiplex PCR. J Clin Microbiol. 2002;40(6):2153-62.

25. Doi Y, Arakawa Y. 16 S ribosomal RNA methylation: emerging resistance mechanism against aminoglycosides. Clin Infect Dis. 2007;45(1):88-94.10. 1086/518605

26. Wachino J, Shibayama K, Kurokawa H, Kimura K, Yamane K, Suzuki S, et al. Novel plasmid-mediated 165 rRNA m1A1408 methyltransferase, NpmA, found in a clinically isolated Escherichia coli strain resistant to structurally diverse aminoglycosides. Antimicrob Agents Chemother. 2007;51(12):44019. https://doi.org/10.1128/aac.00926-07.

27. Doi Y, Wachino Jl, Arakawa Y. Aminoglycoside resistance: the emergence of acquired 165 ribosomal RNA methyltransferases. Infect Dis Clin North Am. 2016;30(2):523-37. https://doi.org/10.1016/j.idc.2016.02.011.

28. Sharma P, Gupta SK, Diene SM, Rolain JM. Whole-genome sequence of Chryseobacterium oranimense, a colistin-resistant bacterium isolated from a cystic fibrosis patient in France. Antimicrob Agents Chemother. 2015;59(3): 1696-706. https://doi.org/10.1128/aac.02417-14.

29. Carattoli A. Resistance plasmid families in Enterobacteriaceae. Antimicrob Agents Chemother. 2009;53(6):2227-38. https://doi.org/10.1128/aac.01707-08.

30. Liu $P$, Li $P$, Jiang $X$, Bi D, Xie $Y$, Tai $C$, et al. Complete genome sequence of Klebsiella pneumoniae subsp. pneumoniae HS11286, a multidrug-resistant 
strain isolated from human sputum. J Bacteriol. 2012;194(7):1841-2. https:// doi.org/10.1128/jb.00043-12.

31. Carrara E, Pfeffer I, Zusman O, Leibovici L, Paul M. Determinants of inappropriate empirical antibiotic treatment: systematic review and metaanalysis. Int J Antimicrob Agents. 2018;51(4):548-53. https://doi.org/10.1016/ j.ijantimicag.2017.12.013

32. Oliva A, Mascellino MT, Cipolla A, D'Abramo A, De Rosa A, Savinelli S, et al. Therapeutic strategy for pandrug-resistant Klebsiella pneumoniae severe infections: short-course treatment with colistin increases the in vivo and in vitro activity of double carbapenem regimen. Int J Infect Dis. 2015;33: 132-4. https://doi.org/10.1016/j.ijid.2015.01.011.

33. Yu L, Zhang J, Fu Y, Zhao Y, Wang Y, Zhao J, et al. Synergetic effects of combined treatment of colistin with meropenem or amikacin on carbapenem-resistant Klebsiella pneumoniae in vitro. Front Cell Infect Microbiol. 2019;9:-422. https://doi.org/10.3389/fcimb.2019.00422.

34. Oliva A, D'Abramo A, D'Agostino C, lannetta M, Mascellino MT, Gallinelli $C$, et al. Synergistic activity and effectiveness of a double-carbapenem regimen in pandrug-resistant Klebsiella pneumoniae bloodstream infections. J Antimicrob Chemother. 2014;69(6):1718-20. https://doi.org/ 10.1093/jac/dku027.

35. El Nekidy WS, Mooty MY, Attallah N, Cardona L, Bonilla MF, Ghazi IM. Successful treatment of multidrug resistant Klebsiella pneumoniae using dual carbapenem regimen in immunocompromised patient. IDCases. 2017:9:535.https://doi.org/10.1016/j.idcr.2017.06.005.

36. Bulik CC, Nicolau DP. Double-carbapenem therapy for carbapenemaseproducing Klebsiella pneumoniae. Antimicrob Agents Chemother, 2011. 55(6):3002-4. https://doi.org/10.1128/aac.01420-10.

37. Galani I, Nafplioti K, Chatzikonstantinou M, Souli M. In vitro evaluation of double-carbapenem combinations against OXA-48-producing Klebsiella pneumoniae isolates using time-kill studies. J Med Microbiol. 2018;67(5):6628. https://doi.org/10.1099/jmm.0.000725

38. Lascols C, Peirano G, Hackel M, Laupland KB, Pitout JD. Surveillance and molecular epidemiology of Klebsiella pneumoniae isolates that produce carbapenemases: first report of OXA-48-like enzymes in North America. Antimicrob Agents Chemother. 2013;57(1):130-6. https://doi.org/10.1128/ aac.01686-12.

39. Giske CG, Froding I, Hasan CM, Turlej-Rogacka A, Toleman M, Livermore D, et al. Diverse sequence types of Klebsiella pneumoniae contribute to the dissemination of blaNDM-1 in India, Sweden, and the United Kingdom. Antimicrob Agents Chemother. 2012;56(5):2735-8. https://doi.org/10.1128/ aac.06142-11.

40. Moubareck CA, Mouftah SF, Pal T, Ghazawi A, Halat DH, Nabi A, et al. Clonal emergence of Klebsiella pneumoniae ST14 co-producing OXA-48-type and NDM carbapenemases with high rate of colistin resistance in Dubai, United Arab Emirates. Int J Antimicrob Agents. 2018. https://doi.org/10.1016/j. ijantimicag.2018.03.003

41. Lee CR, Lee JH, Park KS, Kim YB, Jeong BC, Lee SH. Global dissemination of carbapenemase-producing Klebsiella pneumoniae: epidemiology, genetic context, treatment options, and detection methods. Front Microbiol. 2016;7: 895. https://doi.org/10.3389/fmicb.2016.00895.

42. Cuzon G, Ouanich J, Gondret R, Naas T, Nordmann P. Outbreak of OXA-48positive carbapenem-resistant Klebsiella pneumoniae isolates in France. Antimicrob Agents Chemother. 2011;55(5):2420-3. https://doi.org/10.1128/ aac.01452-10.

43. Tada T, Tsuchiya M, Shimada K, Nga TT, Thu LTA, Phu T, et al. Dissemination of Carbapenem-resistant Klebsiella pneumoniae clinical isolates with various combinations of Carbapenemases (KPC-2, NDM-1, NDM-4, and OXA-48) and 16S rRNA Methylases (RmtB and RmtC) in Vietnam. BMC Infect Dis. 2017;17(1):467. https://doi.org/10.1186/ s12879-017-2570-y.

44. Potron A, Kalpoe J, Poirel L, Nordmann P. European dissemination of a single OXA-48-producing Klebsiella pneumoniae clone. Clin Microbiol Infect. 2011;17(12):E24-6. https://doi.org/10.1111/j.1469-0691.2011.03669.x.

45. Poirel L, Bonnin RA, Nordmann P. Genetic features of the widespread plasmid coding for the carbapenemase OXA-48. Antimicrob Agents Chemother. 2012;56(1):559-62. https://doi.org/10.1128/aac.05289-11.

46. Dolejska M, Brhelova E, Dobiasova H, Krivdova J, Jurankova J, Sevcikova A, et al. Dissemination of IncFII(K)-type plasmids in multiresistant CTX-M-15producing Enterobacteriaceae isolates from children in hospital paediatric oncology wards. Int J Antimicrob Agents. 2012;40(6):510-5. https://doi.org/ 10.1016/j.jjantimicag.2012.07.016.
47. Bonnin RA, Poirel L, Carattoli A, Nordmann P. Characterization of an IncFII plasmid encoding NDM-1 from Escherichia coli ST131. Plos One. 7(4):2012, e34752. https://doi.org/10.1371/journal.pone.0034752.

48. Marquez-Ortiz RA. Genomic epidemiology of NDM-1-encoding plasmids in Latin American clinical isolates reveals insights into the evolution of multidrug resistance. Genome Biol Evol. 2017;9(6):1725-41. https://doi.org/ 10.1093/gbe/evx115

49. Zhang F, Xie L, Wang X, Han L, Guo X, Ni Y, et al. Further Spread of bla NDM-5 in Enterobacteriaceae via IncX3 Plasmids in Shanghai, China. Front Microbiol. 2016;7:424. https://doi.org/10.3389/fmicb.2016.00424.

50. Guven Gokmen T, Nagiyev T, Meral M, Onlen C, Heydari F, Koksal F. NDM-1 and rmtC-Producing Klebsiella pneumoniae Isolates in Turkey. Jundishapur J Microbiol. 2016;9(10):e33990. https://doi.org/10.5812/jjm.33990.

51. Gonullu N, Aktas Z, Kayacan CB, Salcioglu M, Carattoli A, Yong DE, et al. Dissemination of CTX-M-15 $\beta$-Lactamase genes carried on InC FI and FII plasmids among clinical isolates of Escherichia coli in a University Hospital in Istanbul, Turkey. J Clin Microbiol. 2008;46(3):1110-2. https://doi.org/10.1128/ jcm.01974-07.

52. Poirel L, Jayol A, Bontron S, Villegas MV, Ozdamar M, Turkoglu S, et al. The mgrB gene as a key target for acquired resistance to colistin in Klebsiella pneumoniae. J Antimicrob Chemother. 2015;70(1):75-80. https://doi.org/10. 1093/jac/dku323.

53. Zowawi HM, Forde BM, Alfaresi M, Alzarouni A, Farahat $Y$, Chong TM, et al. Stepwise evolution of pandrug-resistance in Klebsiella pneumoniae. Sci Rep. 2015;5:15082. https://doi.org/10.1038/srep15082.

54. Sonnevend A, Ghazawi A, Hashmey R, Haidermota A, Girgis S, Alfaresi M, et al. Multihospital occurrence of pan-resistant Klebsiella pneumoniae sequence type 147 with an ISEcp1-directed blaOXA-181 insertion in the mgrB gene in the United Arab Emirates. Antimicrob Agents Chemother 2017;61(7). https://doi.org/10.1128/aac.00418-17.

55. Mataseje LF, Boyd DA, Fuller J, Haldane D, Hoang L, Lefebvre B, et al. Characterization of OXA-48-like carbapenemase producers in Canada, 201114. J Antimicrob Chemother. 2017. https://doi.org/10.1093/jac/dkx462.

56. Hayashi W, Togashi M, Taniguchi Y, Koide S, Nagano Y, Nagano N. First report of colistin resistance in OXA-181 carbapenemase-producing Klebsiella pneumoniae ST3130 in Japan. J Glob Antimicrob Resist. 2018;12:179-80. https://doi.org/10.1016/j.jgar.2018.01.020.

57. Nahid F, Zahra R, Sandegren L. A blaOXA-181-harbouring multi-resistant ST147 Klebsiella pneumoniae isolate from Pakistan that represent an intermediate stage towards pan-drug resistance. Plos One, 2017. 12(12): e0189438. https://doi.org/10.1371/journal.pone.0189438.

\section{Publisher's Note}

Springer Nature remains neutral with regard to jurisdictional claims in published maps and institutional affiliations.

Ready to submit your research? Choose BMC and benefit from:

- fast, convenient online submission

- thorough peer review by experienced researchers in your field

- rapid publication on acceptance

- support for research data, including large and complex data types

- gold Open Access which fosters wider collaboration and increased citations

- maximum visibility for your research: over $100 \mathrm{M}$ website views per year

At BMC, research is always in progress.

Learn more biomedcentral.com/submission 